\section{RARE DISLOCATIONS.}

By S. M. BRADLEY, F.R.C.S., Senior Assistant-Surgeon to the Royal Infirmary, Manchester.

ABout a year ago, a healthy man aged 35 fell from a scaffolding, dislocating his right shoulder, and was admitted into the Manchester Royal Infirmary the same day. On examination, the head of the humerus was discovered beneath the coracoid process; but so much crepitus was felt, that it was thought that the dislocation was complicated with fracture of the glenoid cavity. Unsuccessful attempts at reduction having been made with the knee and foot in the axilla, he was placed under chloroform to permit a more thorough examination, and also for the purpose, if deemed requisite, of employing the pulleys. Almost immediately after becoming unconscious he ceased to breathe, and all attempts at resuscitation failed : the death was, I believe, reported at the time in the BRITISH MEDICAL JOURNAL. On post mortem examination, it was found that a piece, of the size of an almond, had been chipped off the head of the humerus, and that this fragment lay on the lower edge of the glenoid cavity, while the rest of the head was displaced inwards beneath the coracoid process. Between the two lay the long strap-like tendon of the biceps; hence it is manifest that the more extension was practised the tighter this strap would be drawn, and with this the greater would become the obstacle to reduction. It proved easy, on the other hand, to replace the head of the bone in its socket by carrying the shaft of the humerus upwards, and then rotating inwards, thus unwinding the head from beneath the restraining tendon. The preparation is in the Owens College Museum.

Within the past fortnight, two cases have been admitted into the Infirmary with dislocation of the tibia forwards at the knee-joint. In the first case, the condyles of the femur lay just below and behind the popliteal space, while the head of the tibia formed a prominent ridge anteriorly over the intercondyloid notch. In the second case, the displacement was even more considerable; the limb was shortened to the extent of three inches, and the condyles so sharply defined at the back of the leg as to appear on the point of bursting through the skin; the leg was blue and cold, owing to pressure on the popliteal artery. In both cases, reduction was readily effected by means of simple manual exten. sion under chloroform, and in both pulsation almost immediately returned in the posterior tibial artery. Nearly all pain ceased on the reduction of the displacement, and up to the present time both cases have gone on uninterruptedly well. When we consider, amongst other lesions, that the crucial ligaments must necessarily be completely ruptured in this accident, it is interesting to note, in cases of the kind which have been recorded, that the movements of the limb in the sequel are little affected; flexion, extension, and the characteristic lateral movements all being performed with the same ease and precision as they were prior to the injury.

The dislocations of the shoulder and knee here briefly reported are not unique, but they are rare; and I think the former, at least, is valuable as showing how, in certain cases, manipulation may possibly succeed when extension must certainly fail.

\section{A CASE OF SUDDEN ONSET OF VIOLENT CHOREA DURING AN ATTACK OF ACUTE RHEUMATISM, WITH ARREST OF THE MOVEMENTS UNDER TREATMENT : RECOVERY.}

By J. HYDE HOUGHTON, Surgeon to the Guest Hospital, Dudley.

I AM induced to publish this case on account of its great rarity, and of the interest it possesses touching the question of the connection between rheumatism and chorea. This general connection is admitted and referred to by authors; the first to observe it being, I believe, Dr. Copland, who also refers to cases by Prichard, Rosier, etc. Trousseau speaks of rheumatism as one of the pathological causes of chorea quoting, in support of the proposition, Stoll, Bright, Begbie, and others. Again, Dr. Todd, in his lectures, gives two cases, with comments, to prove the connection; and further insists on the resemblance bitween the two diseases, adducing, as arguments in support of his theory, the condition of the urine, the liability to repeated attacks, and the frequent occurrence of endocardial murmurs in each. Dr. Churchill says very little on the subject ; and Dr. Kirkes is of opinion that the connection is not with rheumatism, but with the endocardial disease. Dr. Tanner again, says : "There seems to be some obscure connection between chorea and rheumatism, the latter disease preceding the former." The connection is thus established by abundant authority, which is con- firmed, no doubt, by the experience of all who have had opportunities of extended observation.

These remarks all refer to the general connection between chorea and rheumatism, in which the former is a consequence of the latter, more or less remote ; but when we come to speak of chorea as part of an attack of acute rheumatism, if I may so speak, at all events coming on during the acute stage, very little seems to be known, and very few cases are on record, so far as $I$ have been able to learn.

CASE.-On August 29th, 1875, I saw Clara B., aged 12, the daugh. ter of a clergyman. She was not supposed to be very ill; but as her father and mother were leaving home, they asked me to see her before they started. The tongue was moist. There was no thirst. The countenance was bright. There was slight pain in both ankles, and under the left malleolus a red spot of the size of a shilling, which was tender. There was well marked murmur, loudest over the left side of the heart. There was no cough; slight dyspnœa; no pain over the chest. Temperature 102 deg.; pulse I2O; respirations 24; urine acid. She had not been well the last day or two, and a few days pre. viously, whilst hot and fatigued, had sat on the grass. She had not had rheumatism before. Alkaline treatment was used freely.

August 30 th. Temperature 103 deg.; pulse 120 ; respirations 20. The urine was very acid; the sweat was distinctly acid. The pain in the joints was better. The murmur was pronounced.

August 3 Ist. The left knee and shoulder were affected.

September 2nd. The urine was neutral, and she had had a good night. There was some dyspnoea at 7 P.M., which was relieved by a sinapism.

September $4^{\text {th. }}$ She had some giddiness, and pain in the side. The physical signs were improved.

September 5 th. The temperature, pulse, and respiration had continued much the same till to-day, when the temperature fell to 99 deg., the pulse to 104, and there was remission of symptoms.

September 6th. Temperature 102 deg.; pulse I20; respirations 48. She awoke much frightened, and had some dyspnœa in the night.

September 8th. She had a bad night, with dyspnoea, delirium, and restlessness. There was a return of pain in one foot, and in the precordial region on inspiration were precordial dulness and extended im. pulse. A blister was applied.

September I 2 th. There was very little change till to day. Temperature 102 deg.; pulse 140; respirations 20.

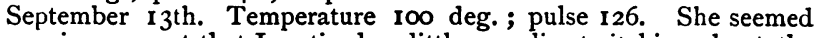
improving, except that I noticed a little peculiar twitching about the face and sudden movements of the head, which I did not regard much, as she had naturally a very sharp quick manner, and so had one of her sisters; and her mother, to whom I mentioned it, did not see anything very unusual in it.

September I 4 th. At four this morning I was called, hearing that the child was furiously delirious. This was not so. She was perfectly conscious, but in a paroxysin of violent chorea; the motions of the fore limbs and whole body being violent. The pains had entirely left the joints. The heat had subsided, but the jactitation was so violent that it was quite impossible to take the temperature, count the pulse, or auscult the chest. She had had no sleep during the night. Dr. Heslop saw her with me. We gave her all the nourishment possible, and liquor morphiæ with quinine and bromide of potassium.

September 15 th. The medicine had made the child very sick, and was discontinued, but the sickness continued; and, in spite of large doses of liquor opii, very little rest was obtained, and she was much the same.

On the 16 th, I gave five grains of chloral and ten of bromide every four hours; and in the afternoon Dr. Heslop again saw her, and concurred in the treatment, suggesting that she should have nutrient enemata with quinine and brandy. Her worst symptom was hurried catching breathing.

September I 7 th. This morning, I found that she took chloral at 4 P.M., and afterwards got some tranquil sleep; again at II P.M., which she vomited; and again at 5 this morning. She had a good night ; chorea was almost gone; the countenance was tranquil. The tongue was furred; she had not much thirst, and took food moderately. She had complained of slight pain in the wrist the first time since the chorea set in. Temperature IoO deg.; pulse I20; respirations 64 ; urine neutral.- IO P.M. She was free from chorea. The countenance was placid. She was sensible and took nourishment freely. She com plained of aphthæ. She had slept nearly all day, and had not taken any medicine since 5 A.M. ; and from this time nothing worthy of record occurred till September 2 rst, when convalescence was completely established. Temperature 98 deg. ; pulse 100 ; respirations 30 . She took food freely, and had not taken any medicine since 5 A.M. on the I 7 th. A loud diffused cardiac murmur continued. From this time 